\title{
Antecedents and the Outcome of Customer Citizenship Behavior in Consumption Virtual Communities: A Theoretical Model ${ }^{*}$
}

\author{
Zhang Yu-hong \\ Faculty of Management and Economics \\ Dalian University of Technology \\ Dalian, China \\ School of Business \\ Beijing Wuzi University \\ Beijing, China \\ yuhong-zh@163.com
}

\author{
Dong Da-hai \\ Faculty of Management and Economics \\ Dalian University of Technology \\ Dalian, China \\ Dongdh@dlut.edu.cn
}

\author{
Liu Sheng-nan \\ Department of Business Administration \\ Guangdong University of Finance \\ Guangzhou, China \\ Liushengfnan@gduf.edu.cn
}

\begin{abstract}
Prior studies have showed that there are different antecedents of two forms of OCB (i.e. OCBO and OCBI) that direct to different objects such as the organization as a whole, superiors and colleagues. In this paper, we classify CCB into CCBO and CCBI according to the multifoci approach in OCB. Based on this classification, we draw on social exchange theory and self-determination theory to investigate the different predictors of CCBO and CCBI and then construct a theoretical model in the context of consumption virtual communities.
\end{abstract}

Keywords-Customer citizenship behaviors; ССВO; ССВI; Consumption virtual communities

\section{INTRODUCTION}

Consumption virtual communities are defined as online communities which are composed of consumers with topics around products, services and consumption experiences [1]. Compared with other virtual communities, consumption virtual communities are undoubtedly of great significance to marketing benefits of the firms providing products /services and the virtual communities themselves. Just like any virtual community, the sustainability and success of consumption virtual communities depend on users' contribution. Most prior studies focus on the consumers' knowledge sharing behaviors in virtual communities [2], but we think, more attention should be paid to another consumer behaviorcustomer citizenship behavior (CCB). Groth (2005) defined CCB as "voluntary and discretionary behaviors of individual customers that are not required for the successful production

Supported by the Project of National Natural Sciences Foundation of China (No. 71272094 and No.71002079) and the Business Operation and Enterprise Service Innovation Platform of Beijing Municipal Commission of Education and/or delivery of the service but that, in the aggregate, help the service organization overall” [3]. Extant researches on CCB show that customers are just like "part-time employees", leading to low marketing cost and promoted operative effectiveness. To date, most studies on CCB are carried out in offline context; no research has been done in virtual communities, especially for consumption virtual communities. In this paper, drawing on organizational behavior research, we posit a typology of CCB and further construct a theoretical model of the antecedents and the outcome of CCB in consumption virtual communities based on social exchange theory and self-determination theory.

\section{CUSTOMER CITIZENSHIP BEHAVIOR: CCBO AND CCBI}

The literatures on organizational citizenship behaviors (OCB) always have a tendency to adopt a multifoci approach. The multifoci approach is a research method to investigate OCB based on the different objects that OCB direct to and benefit separately, such as the organization as a whole, superiors and colleagues. For example, certain OCB may be directed towards the organization, such as providing constructive suggestions for the organization, whereas others may be directed towards specific individuals within the organization, such as doing extra work for superiors or helping coworkers in workgroups. Based on previous research, Williams and Anderson (1991) labeled the above two categories of OCB as OCBO and OCBI. OCBO are behaviors benefit directly to the organization; OCBI are behaviors that immediately benefit specific individuals and indirectly through this means contribute to the organization. It is very important to differentiate OCBO from OCBI because prior studies have showed that there are different antecedents of these two forms of OCB [4]. 
The concept of CCB is a reference to OCB by marketing researchers. Similarly, CCB also direct and benefit to different objects including the organization and the customers of the organization. According to OCB researches, we suggest that CCB that direct to different objects can also have different predictors. But so far, no researchers have classified CCB based on their different objects. Though the literatures investigating antecedents of CCB are relatively rich, because of the lack of the distinction between different objects of CCB, the antecedent discussion of existing literatures is not sufficient or even biased. Some authors give a single concern about the antecedents of CCB directing to the organization (i.e. CCBO) [5] [6]. Others take CCB directing to other customers (i.e. $\mathrm{CCBI}$ ) as a dimension of CCB [3] [7], but fail to distinguish different dimensions to explore their antecedents separately, therefore, the results are likely to mask the differences between the two types of behaviors. In this paper, based on the multifoci approach in OCB, we divide CCB into CCBO (customer citizenship behavior for the organization) and CCBI (customer citizenship behavior for individuals), and first apply this classification to the research of CCB in the consumption virtual communities. We define CCBO as voluntary and discretionary behaviors of individual consumers that direct towards the community and benefit the community directly, such as saying positive words of the community to others or giving constructive suggestions for the improvement of the community. CCBI is defined as voluntary and discretionary behaviors of individual consumers that direct towards other consumers in the community, directly benefit to the individual consumers and indirectly benefit to the community, such as posting to share information, knowledge and consumption experiences with others or making responses to the helping request from other members. In next section, we will investigate the different antecedents of these two behaviors based on this distinction and try to construct a theoretical model of CCB in consumption virtual communities.

\section{A THEORETICAL MODEL}

Social exchange theory [8] has received empirical support across multiple investigations of employee citizenship behaviors. As a reference to OCB theory, most existing CCB literatures also draw on social exchange theory as a theoretical framework to explain the relationship between an organization and its customers. We suppose, in consumption virtual communities, the two relationships of community-customer and customer-customer are all social exchange relationships. Social exchange theory can give a support to both CCBO and CCBI. Hagel and Armstrong (1997) considered that people gathered in virtual communities to meet their wants and needs [9]. In consumption virtual communities, though CCBI benefit the community eventually, it is not the original intention of customers who engage in such behaviors [4]. Those who share their product/service information, knowledge and consumption experiences and help other members must have certain motivations to meet their own needs. Based on selfdetermination theory, we propose four motivations of CCBI in consumption virtual communities: reciprocity, reputation, interest and altruism. As to the social exchange between a consumption virtual community and its members, the community just provides a platform, community members' needs can be met through interactions between each other without the participation of the community. Therefore, CCBO need a more strong relationship between the community and its members. Existing CCB literatures put most emphasis on CCBO and employ relationship quality variables to predict CCBO. In this paper, we take CCBO into a new research context and examine the impact of relationship quality variables including customer satisfaction, trust and perceived community support on CCBO in consumption virtual communities. We begin with the antecedents of CCBO.

\section{A. The Antecedents of CCBO}

1) Community satisfaction. The influence of customer satisfaction on CCBO has been discussed in many articles in CCB, but the results are still not consistent. Gruen (1995) considered that unsatisfied customers would adjust their behaviors of purchasing or leave the specific product/service provider instead of adjusting their citizenship behaviors. Therefore, he posited that satisfaction didn't have a direct impact on CCBO[5]. But, Gruen (1995) didn't examine this proposition empirically. Bettencourt (1997) tried to build a positive relationship between customer satisfaction and customer voluntary performance. However, his empirical results didn't support it. Nevertheless, based on social exchange theory, Groth (2005) empirically testified that customers would engage in a citizenship behavior as a return to the organization when they received treatment exceeding their expectations. Other empirical researches also supported the result of Groth (2005) [10]. Therefore, the impact that satisfaction exerts on CCBO needs to be further explored. We try to investigate the impact of customer satisfaction on CCBO in consumption virtual communities. Sheth and Parvatiyar (1995) suggested that customers with positive and satisfied experiences will engage in behaviors benefit to their relationship with the organization [11]. We think CCBO of community members can be seen as an effort of customers to build and retain a good relationship with the community. Hereby, we propose:

P1: Community satisfaction has a positive impact on CCBO in consumption virtual communities.

2) Community trust. Based on previous marketing literatures on trust, we define community trust as a confidence of community members in the honesty, benevolence and competence of the community to engage in behaviors that benefit both sides of the relationship. The research of Gruen (1995) indicates that trust has a positive impact on CCBO, and the more customers trust in a firm, the more likely customers engage in CCBO [5]. Still, Gruen (1995) didn't test this proposition empirically. Empirical results of Xie, Shen and Liang (2008) show that trust has a direct and positive influence on customer citizenship behaviors on travel websites [12]. In a consumption virtual community, we believe customers will trust in the community when they perceive the honesty and 
benevolence of the community and believe the community will not deceive members or damage interests of them. This kind of trust will encourage members to engage in behaviors beneficial to the community. Therefore, we propose:

P2: community trust has a positive impact on CCBO in consumption virtual communities.

3) Perceived community support. Based on the concept of perceived organizational support (POS) in OCB, Bettencourt (1997) proposed the concept of perceived support for customers (PSC). PSC reflects the relationship between the customer and the firm. According to Bettencourt (1997), a firm's support for customers can be exhibited in a variety of forms including concerning with the customers' needs; attaching importance to customers' feedback; and making effort to give a hand when the customers need. According to social exchange theory, when customers perceived these supports from the firm, they will return in the same way, making feedback on their own initiative, informing the problems they encountered or discovered in the services so that the firm can make a promotion. The empirical evidences of Bettencourt (1997) in a retailing store support a positive impact of PSC on CCBO [6]. We believe, in a consumption virtual community, if members can perceive full supports from the community, they will exhibit behaviors that promote the development of the community. Hereby, we propose:

P3: Perceived community support has a positive impact on CCBO in consumption virtual communities.

\section{B. The Antecedents of CCBI}

Social exchange theory can also give a support for CCBI in consumption virtual communities. Besides, we draw on self-determination theory [13] to explore the motivations of CCBI. Based on self-determination theory, we investigate two extrinsic motivations (i.e. reciprocity and reputation) and two intrinsic motivations (i.e. interest and altruism) of CCBI in consumption virtual communities.

1) Reciprocity motivation. Reciprocity is a basic norm in social communication. The norm of reciprocity specifies that people should help those who have helped them by returning equivalent benefits [14]. Even though exchanges in virtual communities occur between strangers, evidence shows that the norm of reciprocity still works [2]. For those who receive help from others or benefit from others' sharing behaviors will feel a sense of indebtedness, which will lead to a motivation to alleviate it through reciprocation. Moreover, more or less, the members who share or respond to others have an expectation that others will do in the same way. Hereby, we propose:

P4: Reciprocity motivation is positively associated with members' CCBI in consumption virtual communities.

2) Reputation motivation. According to social exchange theory, people involve in social exchanges with an expectation of getting some sort of social rewards (e.g. recognition, status and respect) [8]. Though the environment of virtual community is not real, in which customers are strangers and usually have no opportunity to get to know each other, some studies have shown that people interact with others with the motivation to enhance their status and reputation in the community. Wasko and Faraj (2005) provided evidence that building reputation was a strong motivator for active participation in electronic networks of practice [2]. Hereby, we propose:

P5: Reputation motivation is positively related to members' CCBI in consumption virtual communities.

3) Interest motivation. Based on self-determination theory, interest as an intrinsic motivation is generated without any external pressure and utilitarian motives. Individuals engage in an activity to obtain happiness and satisfaction from the activity itself [13]. Hagel and Armstrong (1997) suggested that virtual communities offered an ideal place for people to share common interests [9]. A virtual community of consumption is set up around a topic of certain products. Community members who visit the community only to search for product information must leave after they find what they need. Only those who have a strong interest in the community topic have the motivation to interact deeply with other members. Hereby, we propose:

P6: Interest motivation is positively associated with members' CCBI in consumption virtual communities.

4) Altruism Motivation. Studies on human altruistic behaviors have shown that helping others can make the helper feel happy and satisfied [15]. Once people do a good thing, they will do more. The idea is supported by strong evidences from the researches on volunteers. In consumption virtual communities, those answering other member's questions or providing information useful to others, usually get appreciation and gratitude from other members, and thus obtain inner happiness and satisfaction. Prior research suggests that enjoying helping others is a major motivation for members to contribute knowledge in virtual communities of practice [2]. Therefore, we propose:

P7: Altruism motivation is positively associated with members' CCBI in consumption virtual communities.

\section{The outcome of CCB: Stickiness intention}

Stickiness is considered as a key factor to the success of e-retailers as well as virtual communities. However, how to make customers stick around a website is still unclear. Stickiness intention is defined as willingness of customers to retain on a website and prolong his/her duration of each stay. Lin (2007) constructed a model to examine the antecedents of customers' intention to stick on a website.The results suggested that the formation of the stickiness was affected by web users' attitude towards a website, trust in a website and the quality of website content [16]. In consumption virtual communities, community members' positive word-of-mouth can increase the popularity and reputation of the community, thereby enhancing the quantity of community visits. Furthermore, community members' useful feedback and constructive suggestions facilitate the promotion of community service, thus enhancing members' satisfaction of the community, which will further increase the revisits and retention to the community. Similarly, community members' sharing and responding behaviors make the community visitors always find the information they want, which also helps to increase revisits and retention to the community. Hereby, we propose: 
P8a: CCBO has a positive impact on customers' stickiness intention to a consumption virtual community.

P8b: CCBI has a positive impact on customers' stickiness intention to a consumption virtual community.

Based on all above discussion, we construct the following theoretical model (see Fig.1):

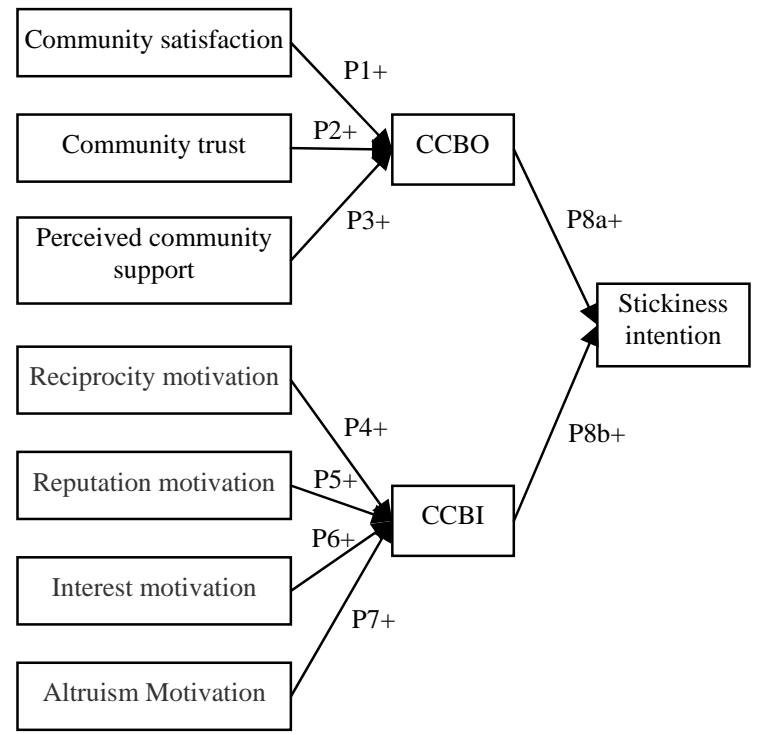

Figure 1. A Theoretical Model of Antecedents and the Outcome of CCB

\section{CONCLUSION}

There are four theoretical contributions of this study. First, we make a distinction between CCBO and CCBI according to their different objects. No research in CCB has ever made such a classification. Second, we construct a theoretical model to find different antecedents and the outcome of CCBO and CCBI in consumption virtual communities. Based on social exchange theory and selfdetermination theory, we find intrinsic and extrinsic motives to meet individual needs are predictors of CCBI, however, CCBO need a more strong relationship between the community and its members. Third, we construct a relationship between $\mathrm{CCB}$ and stickiness intention of members in consumption virtual communities. All these findings provide useful inspiration to community operators. Fourth, we examine CCB in a new context extending the existing research of CCB. In the future, we can make three further researches: first, all the conclusions in this study require further empirical tests; second, the different antecedents of the two types of CCB deserve more theoretical work; third, moderate variables between the antecedents and CCB deserve a further discussion.

\section{REFERENCES}

[1] R. V.Kozinets, "E-tribalised Marketing?The Strategic Implications of Virtual Communities of Consumption," European Management Journal, 1999, 17,pp. 252-64.

[2] M.Wasko and S. Faraj, "Why should I share? Examining social capital and knowledge contribution in electronic networks of practice,” MIS Quarterly, 2005, 29(01): 35-57.

[3] M.Groth,“Customers as good soldiers: Examining citizenship behaviors in internet service deliveries, " Journal of Management, 2005 , 31 (1), pp. 7 - 27.

[4] L. J.Williams and S. E.Anderson, "Job satisfaction and organizational commitment as predictors of organizational citizenship and in-role behaviors”, Journal of Management, 1991, 17, 601-617.

[5] T W. Gruen, "The outcome set of relationship marketing in consumer market” International Business Review, 1995, 4 (4) .pp. 447 -469.

[6] L.A.Bettencourt, "Customer Voluntary Performance:Customers as Partners in Service Delivery”, Journal of Retailing, 1997,73(3), pp.383-406.

[7] Y.Yi and T. Gong, "The antecedents and consequences of service customer citizenship behavior and badness behavior,” Seoul Journal of Business, 2006 , 12 (2) , pp. 145 - 176.

[8] P.M.Blau, Exchange and Power in Social Life.Wiley, New York,1964.

[9] J.Hagel and A. G.Armstrong, "Net gain: expanding markets through virtual communities,” Boston, MA: Harvard Business School Press., 1997

[10] Y.Yi and T. Gong, "If employee go to the extra mile ,Do customers reciprocate with similar behavior ?,” Psychology and Marketing, 2008b , 25 (10), pp. 961 - 986.

[11] J. N.Sheth, and A.Parvatiyar, "Relationship Marketing and Consumer Markets: Antecedents and Consequences,” Journal of Academy of Marketing Science, 1995,Vol. 23, No. 4, pp. 255-271.

[12] Xie Lishan, Shen Wenguo and Liang Xiaodan, "Relationship between Service Justice and Customer Citizenship Behavior-An Empirical Study in Online Service Setting," Management Review, 2008(6), pp.17-24.

[13] E. L .Deci and R. M. Ryan, Intrinsic motivation and selfdetermination in human behavior. New York: Plenum.,1985.

[14] A.W. Gouldner, "The norm of reciprocity" American Sociological Review,1960, 25, pp. 165-178.

[15] D. G.Myers, Social Psychology. McGraw-Hill Co, 2005.

[16] Judy Chuan-Chuan Lin, "Online stickiness: Its antecedents and effect on purchasing intention,” Behaviour \& Information Technology, 2007, 26(6), pp. 507-516. 